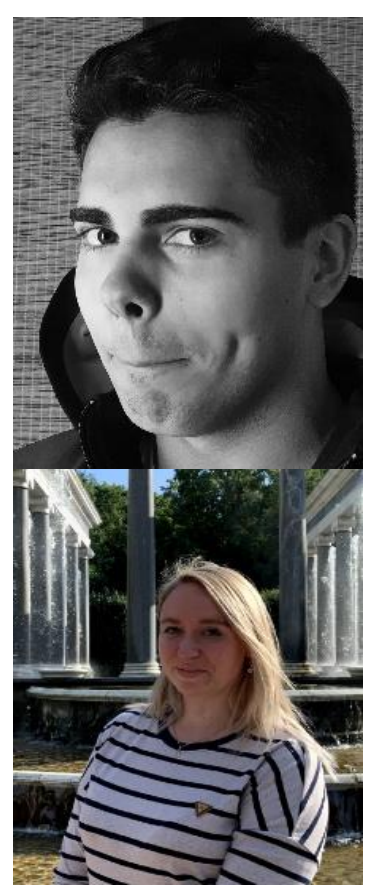

\section{ИССЛЕДОВАНИЕ БИОЛОГИЧЕСКИ АКТИВНЫХ ВЕЩЕСТВ ЗЕЛЕНОГО ЧАЯ}

Д. А. Петрухин, студент 4-го курса, e-mail: denisrussia2000@gmail.com ФГБОУ ВО «Калининградский государственный технический университет»

Е. Э. Киселева, студентка 4-го курса, e-mail: ms.pepper2000@mail.ru

ФГБОУ ВО «Калининградский государственный технический университет»

Е. С. Землякова, канд. техн. наук, доц., e-mail: evgeniya.zemljakova@klgtu.ru ФГБОУ ВО «Калининградский государственный технический университет»

Чай является одним из самых популярных напитков в мире, его получают путем специальной переработки верхних частей побегов (флешей) вечнозеленого чайного растения семейства чайные (Theaceae). Существует множество разновидностей чая, которые классифицируют по типу механической обработки (байховые, прессованные, экстрагированные, ароматизированные). Чай можно также классифицировать по степени ферментации чайного листа: неферментированные (белый и зеленый), ферментированные (черный) и слабоферментированные (желтый и красный). Объектом исследования данной статьи является зеленый байховый чай. В статье осуществлен анализ научной литературы на тему состава биологически активных веществ (БАВ) зеленого чая. Цель практической части исследования заключалась в сравнительном анализе образцов зеленого байхового чая производителей, пользующихся наибольшей популярностью на рынка Калининградской области: Ahmad Tea и Greenfield по органолептической, а также по основным физикохимическим показателям: массовая доля влаги и сухих веществ экстракта, $\mathrm{pH}$, содержания витамина С, танина.

Ключевые слова: зеленый чай, биологически активные вещества, анализ, алкалоиды, флавоноиды, химия чая

\title{
ВВЕДЕНИЕ
}

Все виды чая, кроме травяных сборов, делают из листьев куста китайской камелии. Качество байхового чая зависит от места произрастания, времени сбора, возраста флеша. При производстве зеленого чая флеш фиксируют горячим паром, подсушивают, скручивают, сортируют и сушат, а стадии завяливания листа и его ферментации не включаются в технологический процесс (либо этот процесс занимает не более двух дней).

Зеленый чай богат биологически активными веществами в виде полифенолов и БАВ с антиоксидантными свойствами, которые придают напитку уникальные лечебные свойства. Все они сохраняются в готовом чае вместе с другими полезными компонентами при 
правильной заварке. Тем самым вызван интерес к химическому составу чая и его применению для профилактики различных заболеваний.

\section{ОБЬЕКТЫ ИССЛЕДОВАНИЯ}

В качестве исследуемых объектов выступили образцы зеленого байхового чая производителей, пользующихся наибольшей популярностью на рынке Калининградской области: Ahmad Tea и Greenfield. Исследованы как сухая россыпь, так и приготовленные настои, которые были подвергнуты органолептической оценке, а также определены их основные физико-химические показатели, максимально влияющие на качество напитка: массовые доли влаги и сухих веществ экстракта, содержание танина и витамина $\mathrm{C}, \mathrm{pH}$.

\section{ЦЕЛЬ ИССЛЕДОВАНИЯ}

Целью настоящей работы является: 1) анализ научной литературы в области химического состава зеленого чая, формирование представления о биохимическом потенциале данного напитка, а также о его биологической и пищевой ценности; 2) определение физико-химических показателей качества зеленого чая разных производителей по апробированным методикам с последующим анализом соответствия исследуемых образцов требованиям ГОСТов.

\section{РЕЗУЛЬТАТЫ ТЕОРЕТИЧЕСКОЙ ЧАСТИ}

Анализ научно-технической литературы в области химического состава зеленого чая дает ясное представление о пользе и потенциальном физиологическом воздействии исследуемого продукта на организм человека.

Зеленый чай имеет богатый химический состав. Более 100 взаимосвязанных между собой БАВ, содержащихся в чае, образуют единый комплекс, благодаря чему систематическое употребление данного напитка оказывает благоприятное воздействие на организм, нормализуя обмен веществ [3].

Среди алкалоидов в составе зеленого чая выделяют теофиллин, теобромин и кофеин (рис. 1). Содержание последнего в чае даже больше, чем в кофе или в какао, но его действие на организм более мягкое за счет образования с танином танната кофеина (теин). Именно это соединение ответственно за придание чаю горечи [1].<smiles>Cn1c(=O)c2[nH]cnc2n(C)c1=O</smiles>

Теофнллин<smiles>Nc1nc2[nH]cnc2c(=O)[nH]1</smiles>

Гуанин<smiles>Cn1cnc2c1c(=O)[nH]c(=O)n2C</smiles>

Теобромин<smiles>Cn1c(=O)c2c(ncn2C)n(C)c1=O</smiles>

Кофенн

Рисунок 1 - Алкалоидь, входящчие в состав чая

Другими фитохимическими веществами в составе чая являются флавоноиды (дифенилпропаноиды). Структурные типы флавоноидов изображены на рис. 2. Зеленый чай особенно богат флаван-3-олами (катехинами). Катехины чайного листа обеспечивают наиболее полезные свойства чая. Они снижают хрупкость капилляров, а также их проницаемость. Кроме того, они нормализуют тканевое дыхание и проявляют антиоксидантную активность. Согласно прочим исследованиям катехины защищают генетический аппарат клетки от поражающего действия ионизирующего излучения, а также тормозят развитие таких заболеваний, как болезнь Альцгеймера и Паркинсона [1]. 
В зеленом чае содержатся эпигаллокатехингаллаты, повышающие активность ключевых ферментов остеогенеза, увеличивающие минерализацию костной ткани, блокирующие активность остеокластов. Именно зеленый чай содержит наибольшее количество катехинов и эпигаллокатехингаллатов, что обуславливает его биологическую ценность. Второе место по содержанию данных БАВ принадлежит чаю улун, после которого идет черный чай и на последнем месте - пуэр [1].

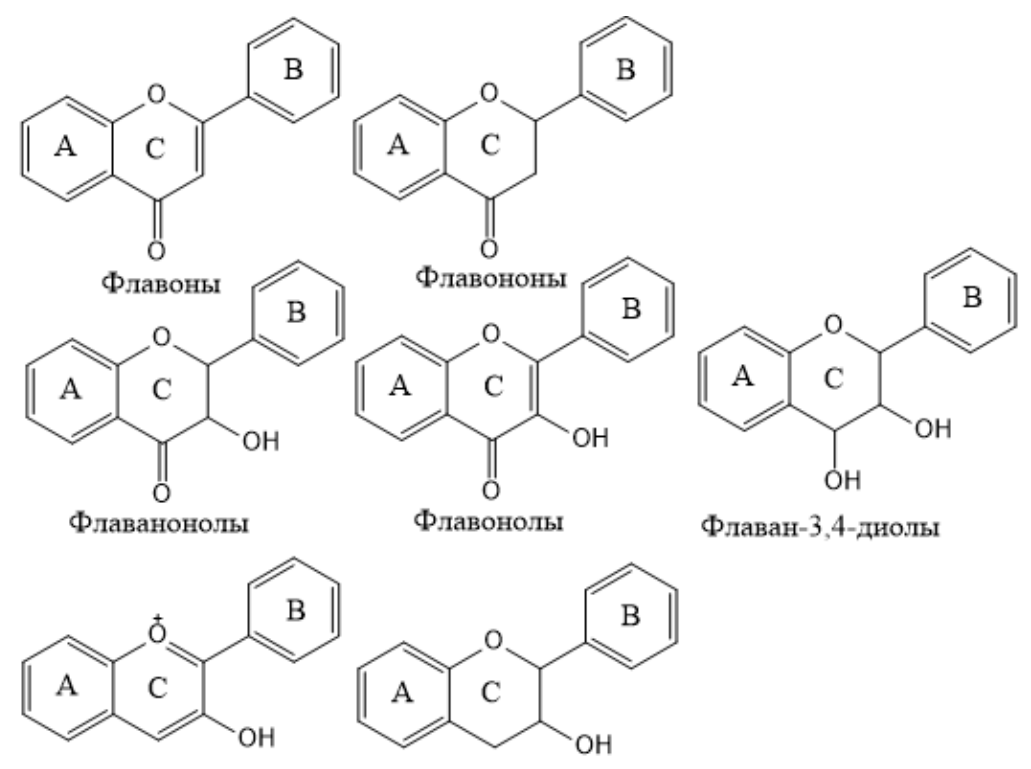<smiles>O=C(/C=C/c1ccccc1)c1ccccc1</smiles>

Флаван-3-олы<smiles>O=C(CCc1ccccc1)c1ccccc1O</smiles><smiles>O=C1/C(=C\c2ccccc2)Oc2ccccc21</smiles>

Халконы

Дигидрохалконы<smiles>O=C1c2ccccc2OCC1c1ccccc1</smiles>

Изофлавононы<smiles>O=c1c(-c2ccccc2)coc2ccccc12</smiles>

Изофлавоны

Рисунок 2 - Структурные семейства флавоноидов

Среди пищевых источников флавоноидов чай занимает особое место, так как, с одной стороны, он является одним из главных источников флавоноидов, а с другой - это второй после воды наиболее употребляемый напиток (при этом 77 \% приходится на черный чай, 20 - на зеленый чай и 3 - на улун). В ряде стран высокий уровень потребления флавоноидов, например, в Японии, обусловлен заметным вкладом чая [1].

Чайные листья богаты белками. Вместе с аминокислотами белковые вещества составляют до $25 \%$ состава листа. Обычно под белками чайного листа понимаются альбумины и глютеины. Последние характерны больше для черного чая, в листьях же зеленого число альбуминов значительно преобладает. Стоит отметить, что повышенное содержание белка в зеленом чае никак не сказывается на его качестве, в то время как для черного чая ситуация обстоит иначе [1].

Среди азотсодержащих компонентов особенно стоит отметить теанин аминокислоту, ответственную за придание особого вкуса зеленого чая. Содержание теанина усиливает вкусовые качества настоев зеленого чая, делая их сладковатыми и пикантными. 
Лучшие сорта китайского чая в Японии содержат до $2 \%$ теанина (в разных сортах содержание этого БАВ варьируется от 1,5 до 3 \%). Поэтому содержание теанина - один из важных показателей качества зеленого чая [1].

В чае присутствуют практически все важные витамины. В зеленом чае, например, в 2-3 раза больше витамина $\mathrm{C}$, чем в лимонах и апельсинах. Обнаружены также витамины А, $\mathrm{E}, \mathrm{D}, \mathrm{K}[1]$.

Среди других БАВ в составе чая следует также упомянуть изопреноидные соединения, которые представлены в основном терпенами и их кислородсодержащими производными - терпеноидами. Данные соединения являются важными вторичными метаболитами в виде систем с сопряженными двойными связями. Они обуславливают ряд жизненно необходимых для растения функций. Терпеноиды являются основными компонентами эфирных масел (главным образом, это монотерпены, сесквитерпены и их всевозможные производные). Замечено, что выделяясь и испаряясь во внешней среде с поверхности листа, эфирное масло создает своего рода облако, снижающее теплопроницаемость воздуха вокруг растения и тем самым предохраняя его от перегревания в дневное время [5-7].

Примерно 0,08 \% эфирного масла содержится в чае. Однако несмотря на это весьма незначительное содержание именно эфирному маслу чая приписывают неповторимый чайный аромат. Эфирные масла присутствуют как в составе черного, так и зеленого чая, однако литературные источники позволяют утверждать о том, что в последнем за обеспечение аромата в большей степени ответственны танины. Красные чаи, напротив, своим ароматом обязаны высокому содержанию эфирных масел [1].

Другими важными терпеновыми соединениями в составе чая являются сапонины тритерпеновые структуры, содержащие углеводные компоненты. В последнее время установлено, что эта группа фитохимических веществ чая обладает антиаллергическим, гипотензивным, противовоспалительным, гиполипидемическим и антиканцерогенным действием [1].

Метаанализ 29 исследований, рассматривающих связь между возникновением колоректального рака и частотой употребления зеленого чая, позволил установить, что он оказывает протективное действие на организм, снижая риск возникновения злокачественных новообразований толстого кишечника [4].

Исследования 2006 года показывают, что зеленый чай оказывает положительный эффект на организм при ожирении и диабете, в значительной степени благодаря эпигаллокатехингаллату, который модулирует работу эндокринной системы, влияет на обмен жиров и углеводов, а также регулирует активность клеток печени, жировых клеток и др. Кроме того, зеленый чай, понижая кровяное давление, уменьшает риск возникновения сердечно-сосудистых заболеваний, что также обусловлено его антидиабетическим эффектом [4].

Таким образом, исходя из химического состава зеленого чая, его пищевую и биологическую ценность можно считать достаточно высокими.

\section{РЕЗУЛЬТАТЫ ИССЛЕДОВАНИЙ}

При органолептической оценке чая определялся внешний вид (уборка) его сухого сбора. Оба образца являются слабоскрученным листовым чаем однородного цвета. Типсы, чайная пыль, грубые листы в чае обнаружены не были.

Приготовление настоев - данный этап осуществлялся следующим образом: от каждого образца чая берется навеска (3 г), которая заливается $125 \mathrm{~cm}^{3}$ свежекипяченой воды. После заварки чая полученный настой сливается в фарфоровую чашку так, чтобы разваренные чаинки не попали в настой. Затем он подвергается органолептической оценке качества - определяется ряд показателей, характеристики которых представлены в табл. 1.

Вкус и аромат чая определяют не сразу после получения настоя, а через 1-1,5 мин. За это время настой успеет остыть, что способствует лучшему улавливанию аромата [2]. 
Таблица 1 - Органолептические показатели качества полученных настоев

\begin{tabular}{|c|c|c|c|}
\hline \multirow{2}{*}{ Название } & \multicolumn{2}{|c|}{ Органолептические показатели качества настоя } \\
\cline { 2 - 4 } & цвет & вкус & аромат \\
\hline $\begin{array}{c}\text { AhmadTea } \\
\text { «Green Tea» }\end{array}$ & $\begin{array}{c}\text { Слабоинтенсивный, } \\
\text { однородный, медного оттенка, } \\
\text { тусклый }\end{array}$ & $\begin{array}{c}\text { Терпкий, } \\
\text { насыщенный }\end{array}$ & Миндальный \\
\hline $\begin{array}{c}\text { Greenfield } \\
\text { «Flying Dragon» }\end{array}$ & $\begin{array}{c}\text { Однородный, с желто-зеленым } \\
\text { оттенком, тусклый }\end{array}$ & $\begin{array}{c}\text { Слаботерпкий, } \\
\text { горьковатый }\end{array}$ & Сырой \\
\hline
\end{tabular}

Исходя из результатов органолептической экспертизы образцов чая, можно заключить: зеленый чай Greenfield «Flying Dragon» не соответствует ГОСТ 32374-2013 по таким показателям, как аромат и вкус настоя. Горьковатый вкус указывает на возможную недоферментатированность чая, слабая терпкость может быть связана с поглощением чаем излишек влаги. Сырой, невыраженный, кажущийся посторонним аромат данного образца следует расценивать как результат неправильного хранения.

Массовую долю влаги в чае определяли следующим образом: навеску (3 г) каждого образца взвешивали с погрешностью не более 0,001 г в предварительно подготовленную бюксу. Открытую бюксу с крышкой помещали в сушильный шкаф с температурой $120 \pm 2{ }^{\circ} \mathrm{C}$. Навеска высушивается в течение одного часа, после чего бюксу закрывают крышкой, охлаждают в эксикаторе и взвешивают. После взвешивания бюкса снова помещается в сушильный шкаф на 30 мин для высушивания пробы до постоянной массы.

Содержание влаги исходя из проделанных операций рассчитывается по формуле:

$$
\mathrm{X}_{1}(\%)=\frac{\mathrm{m}_{1}-\mathrm{m}_{2}}{\mathrm{~m}_{3}} \cdot 100,
$$

где $\mathrm{m}_{1}$ - масса бюксы с навеской до высушивания, г; $\mathrm{m}_{2}$ - масса бюксы с навеской после высушивания, г; $\mathrm{m}_{3}$ - масса навески до высушивания, г.

В составе двух образцов также определялось содержание водорастворимых экстрактивных веществ. Для этого на аналитических весах взвешивается фарфоровая чашка (с точностью 0,0001 г), в которую пипеткой переносят $15 \mathrm{~cm}^{3}$ приготовленного настоя. После этого настой выпаривается до получения сухого остатка. Осуществить данный этап можно с помощью водяной бани или на закрытой плите. Полученный осадок высушивается в сушильном шкафу 2 ч при температуре $103{ }^{\circ} \mathrm{C}$, затем охлаждается в эксикаторе и взвешивается. Данный физико-химический показатель рассчитывался исходя из формулы (2):

$$
\mathrm{X}_{2}(\%)=\frac{\mathrm{a} \cdot \mathrm{b} \cdot 100}{\mathrm{c} \cdot \mathrm{d} \cdot\left(1-0,01 \mathrm{X}_{1}\right)}
$$

где $\mathrm{a}$ - масса сухого остатка, г; $\mathrm{b}$ - объем заварки чая, $\mathrm{cm}^{3} ; \mathrm{c}-$ количество взятого для высушивания экстракта, $\mathrm{cm}^{3} ; \mathrm{d}-$ навеска чая, взятая для приготовления настоя, г; $\mathrm{X}_{1}$ - содержание влаги, \%.

В рамках задач исследования в двух образцах чая также определялось содержание танина (качественно и количественно).

Качественное содержание танина основано на реакционной способности фенольных групп танина связываться с хлоридом железа (III) с образованием темно-фиолетового комплекса. Для этого к 1 мл настоя добавляется 1-2 капли $\mathrm{FeCl}_{3}$. Оба образца дали положительную реакцию в виде образования темно-фиолетового окрашивания.

Количественное определение танина выполнялось по следующей методике: 2,5 г измельченного чая взвешивается с погрешностью не более 0,0002 г, после чего помещается в колбу на 250 мл, которая заполняется 200 мл кипящей дистиллированной воды и ставится на 
водяную баню (45 мин). Полученный экстракт фильтруют через воронку Бюхнера (под вакуумом) в колбу вместимостью 500 мл. Фильтрат после этого переносят в колбу на 250 мл, охлаждают и при $20^{\circ} \mathrm{C}$ доводят дистиллированной водой до метки. Так получают экстракт, который используется для проведения анализа.

Отбирается 1 мл полученного экстракта и помещается в чашку для выпаривания, после чего добавляется 75 мл водопроводной воды, 2,5 мл раствора индигокармина. После этого ведется титрование $0,1 \mathrm{H} \mathrm{KMnO}_{4}$ при постоянном перемешивании. При этом синий окрас раствора постепенно переходит через сине-зеленую, темно- и светло-зеленую в желтую золотистого оттенка (т. е. конец реакции определяют по появлению чисто желтого цвета). Аналогично титруется водопроводная вода в присутствии индикатора индигокармина. Содержание танина определялось по формуле (3):

$$
\mathrm{T}(\%)=\frac{\left(\mathrm{a}-\mathrm{a}_{1}\right) \cdot 0,004157 \cdot \mathrm{n} \cdot 100}{\mathrm{n}_{1} \cdot \mathrm{m}}
$$

где а - количество 0,1н раствора $\mathrm{KMnO}_{4}$, ушедшее на окисление танина, мл; $\mathrm{a}_{1}$ - количество 0,1н раствора $\mathrm{KMnO}_{4}$, ушедшее на титрование воды и индигокармина, мл; 0,004157 - количество танина, которое окисляется 1 мл $0,1 \mathrm{H}$ раствором $\mathrm{KMnO}_{4}$, г; $\mathrm{n}$ - количество полученного экстракта чая, мл; $\mathrm{n}_{1}$ - количество экстракта чая, взятое для испытания, мл; $\mathrm{m}$ - масса абсолютно сухого чая, г.

В составе зеленого чая также определялось содержание аскорбиновой кислоты. Использовался йодометрический метод, в основе которого лежит следующая химическая реакция:

$$
\mathrm{KIO}_{3}+5 \mathrm{KI}+6 \mathrm{HCL} \rightarrow 6 \mathrm{KCL}+3 \mathrm{I}_{2}+3 \mathrm{H}_{2} \mathrm{O}
$$

Для определения аскорбиновой кислоты отбиралось 20 мл фильтрата чая, к которому добавлялось: 1 мл соляной кислоты (2\%-ный раствор); 0,5 мл КІ (1\%-ный раствор) и 2 мл крахмала (0,5\%-ный раствор). Полученную смесь смешивали и титровали 0,001 н раствором $\mathrm{KIO}_{3}$ до устойчивого синего окрашивания. Параллельно ведется контрольное титрование, где 20 мл фильтрата заменяется на 20 мл воды. Формула, использованная для расчета, следующая:

$$
\mathrm{X}=\frac{\left(\mathrm{V}-\mathrm{V}_{1}\right) \cdot 0,088 \cdot 100}{20},
$$

где $\mathrm{V}$ - количество йодата калия $(0,001 \mathrm{H})$, ушедшее на титрование исследуемой пробы, мл; $\mathrm{V}_{1}$ - количество йодата калия $(0,001 \mathrm{H})$, ушедшее на титрование в контрольном опыте, мл; 0,088 - количество аскорбиновой кислоты, соответствующее 1 мл точно 0,001н раствора йодата калия, мг; 20 - объем пробы, взятый на титрование, мл.

За результаты анализов физико-химических показателей принималось среднее арифметическое трех параллельных измерений (доверительной вероятности $\mathrm{P}=0,95$ ).

Таблица 2 - Результаты исследований

\begin{tabular}{|c|c|c|c|c|c|}
\hline $\begin{array}{c}\text { Наименование } \\
\text { образца }\end{array}$ & $\begin{array}{c}\text { Витамин С, } \\
\text { мг\% }\end{array}$ & $\begin{array}{c}\text { Танин, } \\
\%\end{array}$ & $\begin{array}{c}\mathrm{pH} \\
\text { среды }\end{array}$ & $\begin{array}{c}\text { Массовая доля } \\
\text { влаги, \% }\end{array}$ & $\begin{array}{c}\text { Массовая доля сухих } \\
\text { экстрактивных } \\
\text { веществ, \% }\end{array}$ \\
\hline $\begin{array}{c}\text { Ahmad Tea } \\
\text { «Green Tea» }\end{array}$ & 13,2 & 4,157 & 4,0 & 4,23 & 29,87 \\
\hline $\begin{array}{c}\text { Greenfield } \\
\text { «Flying Dragon» }\end{array}$ & 17,6 & 12,471 & 4,0 & 5,42 & 35,33 \\
\hline
\end{tabular}

По результатам физико-химических исследований (табл. 2) можно сделать вывод о том, что образец чая компании Greenfield более молод в сравнении со вторым образцом. 
Возможно, образец Ahmad Теа был изготовлен из более старых и грубых листьев, что сказалось на разнице в массовой доле сухих экстрактивных веществ. Этим же объясняется и содержание танина, а также витамина С (в молодых побегах их накапливается больше). Образец чая Ahmad Теа не соответствует требованиям ГОСТа 32574-2013 по показаниям массовой доли сухих экстрактивных веществ (минимальное их количество должно составлять $33 \%)$.

\title{
ЗАКЛЮЧЕНИЕ
}

По результатам анализа научной литературы сделан вывод о том, что зеленый чай представляет собой биологически ценный продукт, содержащий большое число биологически активных веществ. Действие этих веществ положительно влияет на организм человека. Освоены методики приготовления и определения физико-химических показателей настоев зеленого чая. Исходя из полученных результатов можно заключить, что исследуемые образцы не соответствуют ГОСТу по ряду органолептических и физико-химических показателей качества. Предполагается, что это связано с неправильным сбором, нарушением технологии, а также хранением чайных образцов.

\section{СПИСОК ЛИТЕРАТУРЫ}

1. Афонина, С. Н. Биохимия компонентов чая и особенности его биологического действия на организм (обзор) / С. Н. Афонина, Е. Н. Лебедева, Н. П. Сетко // Оренбургский медицинский вестник - 2017. - T. V, № 4 (20). - С. 17-33.

2. ГОСТ 32374-2013. Чай зеленый. Технические условия. - Взамен ГОСТ 1939-90; ГОСТ 3716-90; введ. 01.07.2015. - Москва: Межгосударственный совет по стандартизации, метрологии и сертификации, 2019. - 5 с.

3. Землякова, Е. С. Биологически активные добавки и композиции из сырья растительного происхождения: учебно-метод. пособие по лабораторным работам для студентов, обучающихся в бакалавриате по направлению подготовки 19.03 .01 Биотехнология (профиль «Пищевая биотехнология») по дисциплине «Биологически активные добавки и композиции из сырья растительного происхождения» / Е. С. Землякова. - Калининград: ФГБОУ ВО «Калининградский государственный технический университет», 2020. - 129 с.

4. Море, Э. Э. Влияние зеленого чая на здоровье человека / Э. Э. Море // Проблемы науки - 2018. - № 3(27). - С. 23-24.

5. Племенков, В. В. Введение в химию природных соединений: учебное пособие для использования в учебном процессе в медицинских и фармацевтических вузах России / В. В. Племенков. - Казань, 2001. - 376 с.

6. Пономарев, Д. А. Основы химии терпенов: учебное пособие / Д. А. Пономарев, Э. И. Федорова. - Сыктывкар: Сыктывкарский лесной институт, 2014. - 56 с.

7. Органическая химия: учебник для вузов: в 2 кн. / под ред. Н. А. Тюкавкиной. Москва: Дрофа, 2008. - Кн. 2: Специальный курс. - 592 с.

\section{A STUDY ON THE BIOACTIVE SUBSTANCES IN GREEN TEA}

\author{
D. A. Petrukhin, student, \\ e-mail: denisrussia2000@gmail.com \\ Kaliningrad State Technical University \\ E. E. Kiseleva, student, \\ e-mail: ms.pepper2000@mail.ru \\ Kaliningrad State Technical University
}




\section{E. S. Zemlyakova, PhD, Associate Professor, e-mail: evgeniya.zemljakova@klgtu.ru Kaliningrad State Technical University}

Tea is one of the most popular drinks in the world, obtained through special processing of the upper parts of the shoots (flushes) of an evergreen tea plant of the tea family (Theaceae). There are many varieties of tea, which are classified according to the type of mechanical processing (long tea, pressed, extracted, flavored). Tea can also be classified according to the degree of fermentation of the tea leaf: unfermented (white and green teas), fermented (black) and low-fermented (yellow and red teas). The research object of this article is green long tea. The article analyzes the scientific literature on the composition of biologically active substances (BAS) of green tea. The purpose of the practical part of the study was a comparative analysis of samples of green long tea from manufacturers that are most popular on the market of the Kaliningrad region: Ahmad Tea and Greenfield in terms of organoleptic, as well as basic physical and chemical indicators: mass fraction of moisture, mass fraction of dry substances of the extract, $\mathrm{pH}$, content of vitamin $\mathrm{C}$, tannin.

Keywords: green tea, biologically active substances, analysis, alkaloids, flavonoids, tea chemistry 